\title{
Lignin extraction from oil palm trunk by Microwave-Alkali technique
}

\author{
Long-Wee Lai ${ }^{1,2}$, Ani Idris ${ }^{2,3 *}$ and Noordin Mohd Yusof ${ }^{4}$ \\ ${ }^{1}$ Faculty of Science and Biotechnology, Universiti Selangor, Bestari Jaya 45600, Malaysia \\ ${ }^{2}$ Departemnt of Bioprocess Engineering, Faculty of Chemical Engineering, Universiti Teknologi Malaysia, Skudai 81310, Malaysia \\ ${ }^{3}$ Institute of Bioproducts Development, Universiti Teknologi Malaysia, Skudai 81310, Malaysia \\ ${ }^{4}$ Department of Materials, Manufacturing and Industrial Engineering, Faculty of Mechanical Engineering, Universiti Teknologi Malaysia, Skudai 81310, Malaysia \\ *Corresponding Author: ani@cheme.utm.my (A. Idris)
}

\section{Article history :}

Received 1 February 2013

Revised 20 July 2013

Accepted 25 July 2013

Available online 15 August 2013

\section{GRAPHICAL ABSTRACT}

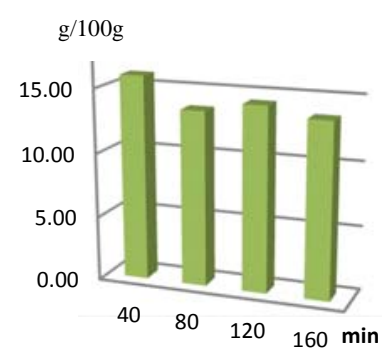

Profile of lignin content $(\mathrm{g} / 100 \mathrm{~g})$ at different duration time

\begin{abstract}
The Klason's lignin content in oil palm tree (Elaeis guineensis) particularly, oil palm trunk (OPT) was intensively investigated in this study. The Microwave-Alkali (Mw-A) pretreatment experiment was designed using Design Expert 7.0 software. The design of experiment (DOE) for this research was established and conducted based on the two-level factorial design with total of eleven runs which included three centre points. All the experimental runs were randomly performed. The independent variables or factors studied were as microwave power, temperature and heating duration and these were coded by high level (+1) and low level (-1) and their corresponding natural variable range were $500-900$ watt, $80-100^{\circ} \mathrm{C}$ and 40-80 min, respectively. The dependent variable or response investigated was the amount of lignin, $Y_{L}$. Prior to Mw-A treatment, the OPT biomass with less than $1.0 \mathrm{~mm}$ (mesh size $<$ No.18) were first presoaked in $2.5 \mathrm{~mol} . \mathrm{L}^{-1}$ sodium hydroxide solution in the ratio of 1:10 (solid: liquid). The amount of lignin present in the washed and dried filtrate samples was subsequently determined. In this case, the total content of lignin determined for untreated and microwave-alkali treated were 17.87 and 13.87 (g/100g biomass), respectively. The analysis of variance performed indicated that temperature $(\mathrm{A})$ and temperature*time (AB) interaction were statistically significant. For the complete model, the F-value for the model is 20.35 whilst the coefficient of determination, $R^{2}=0.9862$ and adjusted coefficient of determination, $R_{A d j}{ }^{2}=$ 0.9377. A reduced model, involving only the significant terms and term supporting the hierarchy, was subsequently developed. This simply show that the lignin content of OPT under Mw-A pretreatment can be modelled and as much as $22.38 \%$ reduction of lignin was attained when the microwave experiment was set at 900 watt, $100^{\circ} \mathrm{C}$ and $80 \mathrm{~min}$, respectively.
\end{abstract}

Keywords: Klason's lignin, Oil palm trunk, Microwave-alkali technique, Factorial design, Sodium hydroxide

(c) 2014 Penerbit UTM Press. All rights reserved http://dx.doi.org/10.11113/mjfas.v10n2.56

\section{INTRODUCTION}

Lignocellulosic materials serve as an alternative renewable source to replace the fossil fuel. This biomass mainly comes from forestry wastes, agricultural residues, commercial crops, waste paper and has drawn attention of many parties [1]. Currently, numerous research scrutinise have been done as its potential use as a starting material for bioenergy or biofuel and other high value added bioproducts such as bioplastics and biochemicals [2]. Lignocellulosic biomass is not only a cheap substrate source in terms of cost but also possesses renewable character that is available throughout the year [3]. The yearly supply of lignocelluloses is approximately 200 billion tonnes worldwide. Due to its abundance, various researches on conversion of lignocellulosic biomass into value added products are intensively investigated.

Unfortunately, lignocellulosic materials are inherently recalcitrant to biodegradation, due to presence of lignin, crystalline cellulose and the complicated covalent cross-linkages between lignin and hemicellulose in the plant cell wall [4]. Typically, the lignocelluloses are first pretreated to destroy the recalcitrant structure in between cellulose, hemicellulose and lignin. This would facilitate the enzyme to attack the polymeric carbohydrate (cellulose) and then turn it into monomeric sugar (glucose). The glucose produced serves as an intermediate that can be used by most microorganisms to emanate bio-products during fermentation. However, the lignin component in biomass is responsible to impart strength to plant cell walls so as to protect cellulose and hemicelluose from enzymatic degradation. This would lead to impede the enzymatic hydrolysis efficiency by non-productive adsorption enzymes [5,6]. Therefore, most pretreatment protocols involve physical, chemical, biological and its combinations are aimed to remove the lignin content in biomass sample.

Nowadays, a number of approaches have been proposed and conducted for lignocelluloses pretreatment, some of which are under intensive investigation on both labscale and pilot scale levels. Generally, these pretreatment 
protocols can be categorized as biological, chemical, physical and thermal processes [7]. Each pretreatment method has its own pros and cons. For instance, biological pretreatment such as lignin degradation by white-rot fungi offers a low chemical and energy consumption but it requires a longer degradation time [8]. The performance of physical method such as milling is poor and results in low outcome [9]. Hot water treatment is effective but energy requirement is too high [10]. Chemical pretreatment is the most promising option so far. Approaches being investigated include dilute acid hydrolysis [11], ammonia fiber explosion [12], alkali solution and organosolv processes [13]. However, the drawback of using chemical pretreatments are relatively low sugar yields, high processing cost, non-environmental friendly to motherearth due to the use of toxic chemicals and etc.

Microwave-assisted reaction gains more popularity recently. Many studies on microwave-assisted reactions have been published since 1985 [14]. Microwave heating uses radiation to speed-up the chemical reaction compared to conventional heating. Furthermore, the technology developments have enabled microwave to be equipped with temperature sensor, power adjustment, stirrer/magnetic speed and time controllers and on-site cameras to observe the reaction occurring inside the microwave hood. All these make microwave as an advanced tool in accelerating chemical reaction. Recently, Hamzah et al. in 2009 [15] has pretreated the oil palm empty fruit bunch (OPEFB) biomass using microwave-alkali pretreatment.

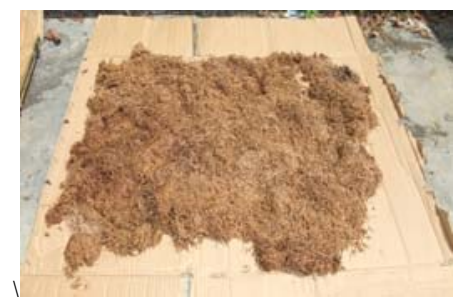

(a)
Besides OPEFB and oil palm frond (OPF), OPT can be another source of lignocellulosic material and the annual oil palm trunk (OPT) residue is approximately 65.46 million tonnes (dry weight) in Malaysia [16] and so far there is no data of microwave-assisted pretreatment work being done on OPT. Hence OPT is selected in this study to provide a preliminary data for future investigation. An experimental framework was established using a two-level factorial design to determine optimal microwave-alkali pretreatment conditions for OPT. All terms, model, interaction effects were statistically analyzed using Design Expert software.

\section{EXPERIMENTAL}

\subsection{Raw material}

The oil palm trunk (OPT) biomass fibre was collected from Felda palm oil plantation, Tenggaroh, Johor, Malaysia. The biomass fibres were washed to remove unwanted dirt, soil, dust and insects prior to air-drying under sunlight as shown in Fig. 1 (a). The dried OPT fibre was then grounded using disk mill (FFC-15, China). Fig. 1 (b) showed the sieved OPT biomass in a particle size less than $1.0 \mathrm{~mm}$ (mesh size< No.18). The sieving process was done using Restuch sieve shaker (AS 200 basis, Germany). The powdered sample was dried in drying oven at $60^{\circ} \mathrm{C}$ for at least $16-18 \mathrm{~h}$ prior to lignin analysis as described by Lai and Idris in 2013 [17]. The rest of the sieved sample was stored in an air-tight container at room temperature.

Fig. 1 Oil palm trunk biomass. (a) Proses of dying oil palm trunk fibre under sunlight, (b) Powdered OPT biomass with particle size $<1.0 \mathrm{~mm}$.

\subsection{Chemical reagents}

All chemicals used in the experiments such as ethanol $\left(\mathrm{C}_{2} \mathrm{H}_{5} \mathrm{OH}\right)$, toluene $\left(\mathrm{C}_{7} \mathrm{H}_{8}\right)$, sulphuric acid $\left(\mathrm{H}_{2} \mathrm{SO}_{4}\right)$ and sodium hydroxide $(\mathrm{NaOH})$ were of analytical grade, high purity and purchased from Sigma-Aldrich (M) Sdn. Bhd.

\subsection{Design of experiments}

The experimental design was constructed using Design Expert ${ }^{\circledR} 7.0$ software. Two-level factorial design was employed to study the effect of selected process parameters. The process parameters (variables) were microwave power (MW, watt), temperature $\left(T,{ }^{\circ} \mathrm{C}\right)$ and duration $(t, \mathrm{~min})$. This study was performed in eleven runs which included three centre points. Each variable was investigated at two levels i.e. high and low, coded by $(+1)$ and $(-1)$, respectively. The response variable investigated was the amount of lignin, $Y_{L}$. Table 1 shows the actual factor levels corresponding to coded factor levels for the two-level factorial design.

Table 1 Actual factor levels corresponding to coded factor levels for two-level factorial design

\begin{tabular}{clcc}
\hline Factor & \multicolumn{1}{c}{ Description } & $\mathbf{- 1}$ & $\mathbf{+ 1}$ \\
\hline A & Temperature, $T\left({ }^{\circ} \mathrm{C}\right)$ & 80 & 100 \\
B & Time, $t$ (min) & 40 & 80 \\
C & Microwave power, $M W$ (watt) & 500 & 900 \\
\hline
\end{tabular}

\subsection{Pretreatment of biomass}

The pretreatment process was conducted as described by Hamzah et al. in 2009 [15]. A total of $20.0 \mathrm{~g}$ biomass sample was pre-soaked in $200 \mathrm{ml}$ of $2.5 \mathrm{M}$ sodium hydroxide 
$(\mathrm{NaOH})$ solution for 2.0 h prior to microwave heating. Fig. 2 illustrated the outlook of microwave that has been used to perform the experiment under normal pressure

(Sineo Chemistry Technology Microwave: MAS-II, China). The Sineo's microwave possesses basic controller functions such as temperature, time and power control that enable users to adjust to the desired setting points. In this investigation, the operating conditions such as microwave power, temperature and duration were set according to the three factor, two-level factorial design with three centre points as tabulated in Table 2. Upon completion, the slurry was first cooled to room temperature.

The $\mathrm{NaOH}$ solution was then filter-off using a Whatman filter paper, grade no 3. Residue was washed under running tap water and followed by distilled water to give a neutral $\mathrm{pH}$ value of filtered solution. The biomass was then dried to constant weight and kept for determination of lignin content.

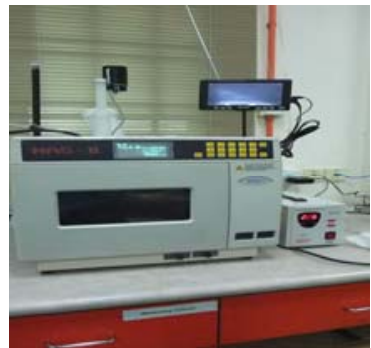

Fig. 2 Mirowave set up used in the experiment.

Table 2 Experimental design and amount of lignin (g/100g) for each experimental run

\begin{tabular}{ccccc}
\hline Run & $\begin{array}{c}\text { Temperature, } \\
T\left({ }^{\circ} \mathrm{C}\right)\end{array}$ & $\begin{array}{c}\text { Duration, } \\
t(\mathrm{~min})\end{array}$ & $\begin{array}{c}\text { Microwave } \\
\text { power, } \\
M W(\text { watt })\end{array}$ & $\begin{array}{c}\text { Lignin } \\
(\mathrm{g} / 100 \mathrm{~g})\end{array}$ \\
\hline 1 & 80 & 80 & 500 & 16.01 \\
2 & 100 & 40 & 500 & 15.01 \\
3 & 90 & 60 & 700 & 14.92 \\
4 & 90 & 60 & 700 & 14.49 \\
5 & 100 & 80 & 900 & 13.87 \\
6 & 80 & 40 & 900 & 16.77 \\
7 & 90 & 60 & 700 & 14.96 \\
8 & 80 & 80 & 900 & 17.58 \\
9 & 100 & 40 & 900 & 16.00 \\
10 & 100 & 80 & 500 & 14.71 \\
11 & 80 & 40 & 500 & 15.72 \\
\hline
\end{tabular}

\subsection{Determination of acid-insoluble lignin}

Prior to lignin quantification, the biomass sample has to undergo the Soxhlet extraction process in order to remove any impurities. The extraction process was conducted as described by TAPPI test method 1997 [18]. The solvents used were ethanol and toluene in the ratio of 1:1 (total of $200 \mathrm{ml}$ in this study) for $8.0 \mathrm{~h}$. Upon completion, extracted oil palm trunk biomass was dried to constant weight and used for lignin test. The acid insoluble lignin or Klason's lignin content was determined based on TAPPI test method 2002
[19]. A total of $1.0 \mathrm{~g}$ OPT extracted biomass was treated with $15 \mathrm{ml}$ of $72 \%$ sulphuric acid solution. The mixture was placed on a stirrer plate with gentle magnetic stirring at ambient temperature for $2.0 \mathrm{~h}$. After $2.0 \mathrm{~h}$, hot distilled water was added to the mixture so as to bring down the acid concentration to $4 \%$. It was followed by immediate heating the mixture in a water bath at $100^{\circ} \mathrm{C}$ for $4.0 \mathrm{~h}$. After that, the residue was filtered, washed with hot distilled water to remove excess acid and dried to constant weight. The amount of lignin residue in biomass is determined gravimetrically as follows:

Weight of filter paper plus lignin - Weight of filter paper x $100 \%$ $1.0 \mathrm{~g}$ initial sample weight

\section{RESULTS \& DISCUSSION}

The lignin amounts obtained were filled into the Design Expert software for further analysis. The results of the analysis of variance (ANOVA) performed were summarized using an ANOVA table shown in Table 3.

It can be seen that the main effect; temperature (A) and two-factor interaction effect; temperature*time (AB), were statistically significant where their $p$-values (also known as the 'Prob $>F$ ' value) were 0.0127 and 0.0409 respectively. According to Montgomery [20], any $p$-value of more than 0.05 can be considered to be statistically insignificant. In this study, the $p$-value for the main factors such as time (B), 0.2129; power (C), 0.0641; interaction terms such as temperature*power (AC), 0.0787, time*power (BC), 0.2175 and temperature*time*power (ABC), 0.0859 were shown to be statistically insignificant.

Table 3 Analysis of variance (ANOVA) for complete model

\begin{tabular}{cccccc}
\hline Source & $\begin{array}{c}\text { Sum of } \\
\text { Square }\end{array}$ & Df & $\begin{array}{c}\text { Mean } \\
\text { Square }\end{array}$ & $\begin{array}{c}F \\
\text { value }\end{array}$ & $\begin{array}{c}p \text {-value } \\
\text { Prob }>F\end{array}$ \\
\hline Model & 9.67 & 7 & 1.38 & 20.35 & 0.0476 \\
A-Temp. & 5.27 & 1 & 5.27 & 77.54 & 0.0127 \\
B-Time & 0.22 & 1 & 0.22 & 3.26 & 0.2129 \\
C-Power & 0.96 & 1 & 0.96 & 14.13 & 0.0641 \\
AB & 1.56 & 1 & 1.56 & 22.94 & 0.0409 \\
AC & 0.76 & 1 & 0.76 & 11.23 & 0.0787 \\
BC & 0.21 & 1 & 0.21 & 3.16 & 0.2175 \\
ABC & 0.69 & 1 & 0.69 & 10.17 & 0.0859 \\
Curvature & 1.84 & 1 & 1.84 & 27.12 & 0.0349 \\
Pure Error & 0.14 & 2 & 0.068 & & \\
Cor Total & 11.65 & 10 & & & \\
\hline
\end{tabular}

Tan et al. [21] also reported that when a model has a $p$-value of lower than $0.05(p<0.05)$, then this indicates that there is only a $5 \%$ chance that a 'Model $F$-value' could occur because of noise. In this case, the model and curvature were shown to be statistically significant where their $p$-value < 0.05 (0.0476-Model and 0.0349-curvature). Moreover, The "Model F-value" of 20.35 implied that the model was significant and there was only a $4.76 \%$ chance that a "Model $F$-Value" this large could occur due to noise. On the other hand, the "Curvature F-value" which possesed 27.12 was also indicated that the significant curvature in the design space (as measured by difference between the average of the 
center points and the average of the factorial points). Up to only $3.49 \%$ chance that a "Curvature F-value" this large could occur due to noise.

Equations (1) and (2) were the models for amount of lignin content, $Y_{L}$ in term of coded and actual parameter.

Amount of lignin, $Y_{L}=+15.71-0.81 * \mathrm{~A}-0.17 \quad * \mathrm{~B} \quad+0.35 * \mathrm{C} \quad-$ $0.44 * A * B-0.31 * A * C-0.16 * B * C-0.29 * A * B * C$

(response model for $Y_{L}$, coded parameters)

Amount of lignin, $Y_{L}=+26.69750-0.14912 *$ Temp. -0.24375 *Time $-0.021575 *$ Power +2.93437Exp-003*Temp.*Time +2.86250 Exp-004*Temp. *Power+6.20000Exp-004*Time*Power -7.34375Exp-006 *Temp.*Time*Power

(response model for $Y_{L}$, actual parameters)

Although time (B) is insignificant, its interaction, temperature*time $(\mathrm{AB})$ is significant thus time is included in the reduced model in order to retain the model hierarchy. On the other hand, the main effect power (C), interaction-terms of temperature*power (AC), time*power (BC) and temperature*time* power (ABC) are insignificant and therefore are being excluded from reduced model. Therefore, the new reduced response models were proposed as described in equations (3) and (4) to measure the lignin content in treated OPT biomass in term of coded and actual parameter.

Amount of lignin, $Y_{L}=+15.71-0.81 * \mathrm{~A}-0.17 * \mathrm{~B}-0.44 * \mathrm{~A} * \mathrm{~B}$

(reduced response model for $Y_{L, \text { coded parameters) }}$

Amount of lignin, $Y_{L}=+26.69750-0.14912 *$ Temp. 0.24375*Time-2.93437x10-3*Temp.*Time

(reduced response model for $Y_{L \text {, actual parameters) }}$

By following the preset microwave-alkali heating conditions, one should be able to remove lignin up to $22.38 \%$ in Mw-A treated sample if compared to native OPT. However, there is a 1.38-6.23\% variation that occur might be due to noise that cannot be explained by the model itself. The high $R^{2}$ and $R_{\text {Adj }}{ }^{2}$ values $(0.9862,0.9377)$ specify that the model obtained will be able to give a convincingly good estimate of response of the system within the range studied. This finding signifies that the correlation between experimental and the predicted value could be accepted. Apart from that, the " $A_{\text {deq }}$ Precision" measures the signal to noise ratio. Usually, a ratio greater than 4.0 is desirable. In this study, ratio of 15.7400 was recorded and indicated an adequate signal. Hence, this model can be used to navigate the design space.

Another experimental work was established to reaffirm the insignificant influence of time factor in oil palm trunk pretreatment. This experiment was set at different duration time, i.e. 40, 80, 120 and 160 min with constant microwave power and temperature at 900 watt and $100^{\circ} \mathrm{C}$, respectively.

Based on Fig. 3, it was noticed that the Klason's lignin content dropped from 40 to $80 \mathrm{~min}$ (15.92 to $13.57 \mathrm{~g} / 100 \mathrm{~g}$ ). The reduction of lignin $(14.76 \%$ in this case) may be attributed to longer reaction conditions. Surprisingly, when the reaction was extended to $120 \mathrm{~min}$, the percentage of reduction was less pronounced i.e. only $10.05 \%$ or equivalent to $14.32 \mathrm{~g} / 100 \mathrm{~g}$ of lignin content was attained in the microwave-alkali treated oil palm trunk sample. However, when the duration was set at $160 \mathrm{~min}$, lignin content was recorded at $13.57 \mathrm{~g} / 100$. It was only $2.16 \%$ of increment on lignin removal if compared to DOE run-5 (13.87g/100g) as shown in Table 2. Since the longer reaction time was not giving great impact to reduce the lignin content and shorter duration would be more economical in term of power consumption. Therefore, shorter duration with higher microwave power and temperature was required to achieve the maximum lignin removal.

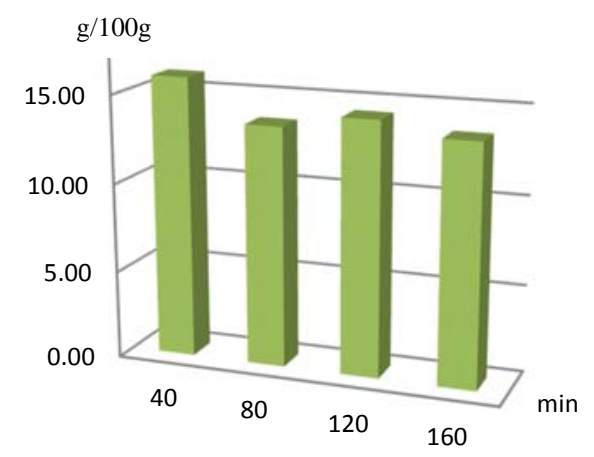

Fig. 3 Profile of lignin content (g/100g) at different duration: time $(t)=40,80,120,160 \mathrm{~min}$ at constant temperature $(T), 100{ }^{\circ} \mathrm{C}$ and microwave power $(M W), 900$ watt.

Table 4 shows the lignin content in oil palm trunk (OPT) biomass before and after pretreatment. A total of $17.87 \mathrm{~g} / 100 \mathrm{~g}$ lignin was present in the raw OPT if compared to $\mathrm{Mw}$-A treated OPT i.e. $13.87 \mathrm{~g} / 100 \mathrm{~g}$. The results indicated that $\mathrm{Mw}$-A heating is only able to remove $22.38 \%$ of lignin in OPT. This is because lignin is a highly cross-linked aromatic polymer based on phenylpropanoid units acting as 'glue' that binds tightly to cellulose and hemicellulose [22].

Lai and Idris in 2013 [17] also stated that higher lignin content in oil palm trunk biomass sample was undesirable and has several disadvantages such as lignin would limit the biodegradability of lignocellulosic biomass in the subsequent enzymatic hydrolysis process. According to the review by Hendriks and Zeeman in 2009 [23], lignin removal was sufficient in low heating pretreatment processes for lowlignin biomass compounds, but not for high-lignin contained biomass. Since OPT biomass was the trunk of oil palm trees, the encrusted lignocellulosic polymer contained high-lignin and thus might require more harsher conditions such as temperature $\left(>160{ }^{\circ} \mathrm{C}\right)$ in order to achieve higher lignin removal [24]. 
However, Hamzah et al. in 2009 [15] was able to remove lignin content in oil palm empty fruit bunch (OPEFB) to as low as $7.56 \mathrm{~g} / 100 \mathrm{~g}$ by using microwave-alkali heating pretreatment. Rahman et al. in 2012 [25], claimed that the difference in the amounts removed may be attributed to the different proportions components in the fibre which depends on nature and age of plant, source of fibre and the extraction conditions used to obtain fibre.

Table 4 Lignin content in of oil palm trunk (OPT)

\begin{tabular}{lc}
\hline Pretreatment Type & g/100g biomass \\
\hline Raw OPT & 17.87 \\
Mw-A treated OPT & 13.87 \\
\hline
\end{tabular}

\section{CONCLUSION}

A microwave-alkali heating pre-treatment process could be considered as an alternative process in breaking lignin compound in oil palm trunk sample. This is because microwave heating is relatively simple, easy and rapid protocol. By using this approach, treated oil palm trunk would be more accessible for enzyme hydrolysis reaction in later process. In conclusion, the $\mathrm{Mw}-\mathrm{A}$ technique is successfully modelled using two-level factorial design. The removal of lignin up to $22.38 \%$ is attained in DOE when the microwave operating conditions is set at 900 watt, $100{ }^{\circ} \mathrm{C}$, and $80 \mathrm{~min}$, respectively.

\section{ACKNOWLEDGEMENT}

The authors would like to thank Department of Bioprocess Engineering, Faculty of Chemical Engineering, Universiti Teknologi Malaysia for the facilities as well as to Ministry of Higher Education (MOHE), Malaysia vot 02H85 for funding the project. Special thanks to Mr. Zaizul Azizi Zaman and Mr. Faisal Abdul Rahman, Felda Palm Industries Sdn. Bhd. who have provided the oil palm trunk sample for this investigation.

\section{REFERENCES}

[1] K. David, and A. J. Ragauskas, Energy Environ. Sci., 3 (2010) 1182.

[2] J. H. Clark, J. Chem. Technol. Biotechnol., 82 (2007) 603

[3] Y. H. P. Zhang, J. Ind. Microbiol. Biotechnol., 35 (2008) 367.

[4] X. D. Hou, T. J. Smith, N. Li, and M. H. Zong, Biotechnol. Bioeng., 109 (2012) 2484.

[5] A. R, Esteghlalian, V. Srivastava, N. Gilkes, D.J. Gregg, and J.N. Saddler, ACS Symp. 769 (2000) 100.

[6] P, Sannigrahi, D. H. Kim, S. Jung, and A. Ragauskas, Energ. Environ. Sci., 4 (2011) 1306.

[7] B. Yang, and C. E. Wyman, Biofuels Bioprod. Bioref., 2 (2008) 26.

[8] A. I. Hatakka, Eur. J. Appl. Microbiol. Biotechnol., 18 (1983) 350.

[9] D. B. Rivers, and G. H. Emert, Biotechnol. Lett., 9 (1987) 365.

[10] G. P. van Walsum, S. G.Allen, M. J. Spencer, M. S. Laser, M. J. Antal, and L. R. Lynd, Appl. Biochem. Biotechnol., 57 (1996) 157.

[11] K. Grohmann, R. Torget, and M. Himmel, Biotechnol. Bioeng., 15 (1985) 59.

[12] M. W. Lau, PhD Thesis, (2010) Michigan State University, United States.

[13] W. E. Kaar, and M. T. Holtzapple, Biomass Bioenerg., 18 (2000) 189.

[14] M. Nuchter, B. Ondruschka, W. Bonrath, and A. Gum, Green Chem., 6 (2004) 128.

[15] F. Hamzah, A. Idris, R. Rashid, and S. J. Ming, J. Appl. Sci., 9 (2009) 3086.

[16] Malaysia Palm Oil Board (MPOB) (2001). Available from http://www.mpob.gov.my. Accessed 18 ${ }^{\text {th }}$ Sept 2012.

[17] L-W. Lai, and A. Idris. Bioresources, 8 (2013) 2792.

[18] TAPPI test method, Solvent extractives in wood and pulp, (1997) T204cm-97.

[19] TAPPI test method, Acid insoluble lignin in wood and pulp, (2002) T222om-02.

[20] D. C. Montgomery, Introduction to statistical quality control, John Wiley and Sons, New York, (2005) p 18

[21] H. T. Tan, K. T. Lee, and A. R. Mohamed, Carbohyd. Polym., 83 (2011) 1862.

[22] R. P. Chandra, R. Bura, W. E. Mabee, A. Berlin, X. Pan, and J. N. Saddler, in: L. Olsson (Ed.), Biofuels, Springer-Verlag, Berlin, 2007, p. 67.

[23] A. T. W. M. Hendriks, and G. Zeeman, Bioresour. Technol., 100 (2009) 10.

[24] W.H. Chen, Y. J. Tu, and Y. J. Sheen, Appl. Energy, 88 (2011) 2726.

[25] M. B. A., Rahman, Z. I. Ishak, D. K. Abdullah, A. M. A. Aziz, M. I. Basri, and A. B. Salleh, J. Oil Palm Res., 24 (2012)1267. 